(2) OPEN ACCESS

${ }^{1}$ Department of Internal Medicine I, Gastroenterology, Hepatology, Endocrinology \& Metabolism, Medical University of Innsbruck, Innsbruck, Austria ${ }^{2}$ Department of Laboratory Medicine, Medical University of Vienna, Vienna, Austria ${ }^{3}$ Department of Dermatology, Medical University of Vienna, Vienna, Austria

\section{Correspondence to}

Professor Timon E. Adolph,

Department of Internal Medicine I, Gastroenterology, Hepatology, Endocrinology \& Metabolism, Medical University of Innsbruck, Innsbruck, Austria; timon-erik.adolph@i-med.ac.at

Received 14 April 2021 Accepted 2 June 2021 Published Online First 18 June 2021

\title{
Calprotectin: from biomarker to biological function
}

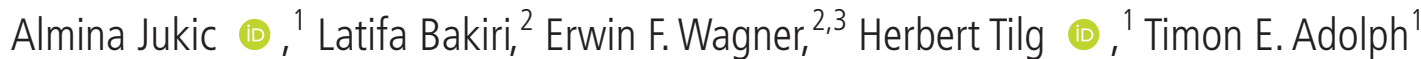

\section{ABSTRACT}

The incidence of inflammatory bowel diseases (IBD) emerged with Westernisation of dietary habits worldwide. Crohn's disease and ulcerative colitis are chronic debilitating conditions that afflict individuals with substantial morbidity and challenge healthcare systems across the globe. Since identification and characterisation of calprotectin (CP) in the 1980s, faecal $\mathrm{CP}$ emerged as significantly validated, non-invasive biomarker that allows evaluation of gut inflammation. Faecal CP discriminates between inflammatory and non-inflammatory diseases of the gut and portraits the disease course of human IBD. Recent studies revealed insights into biological functions of the $\mathrm{CP}$ subunits S100A8 and S100A9 during orchestration of an inflammatory response at mucosal surfaces across organ systems. In this review, we summarise longitudinal evidence for the evolution of CP from biomarker to rheostat of mucosal inflammation and suggest an algorithm for the interpretation of faecal CP in daily clinical practice. We propose that mechanistic insights into the biological function of $\mathrm{CP}$ in the gut and beyond may facilitate interpretation of current assays and guide patient-tailored medical therapy in IBD, a concept warranting controlled clinical trials.

\section{INTRODUCTION}

Inflammation describes an evolutionarily conserved process, which is characterised by the activation of innate and adaptive immune cells to protect the host against a wide range of potential threats. If such responses spiral out of control, dysregulated chronic inflammation turns into a detrimental condition underlying the pathophysiology of many human diseases. ${ }^{12}$ Recent advances fostered our cellular and molecular understanding of unresolved inflammation and consequently, anti-inflammatory targeted therapies, for example, for human inflammatory diseases of the skin, joints and gut have substantially changed clinical practice over the last decade. However, many inflammatory diseases are still poorly controlled, partly because the underlying disease trigger(s) remain enigmatic.

Inflammatory bowel diseases (IBD), including Crohn's disease (CD) and ulcerative colitis (UC), are characterised by chronic remittent episodes of inflammation in and beyond the GI tract. ${ }^{3}$ Recent insights have revealed the complex nature of IBD with a genetic underpinning that cannot explain the majority of cases. ${ }^{45}$ In line with this, a rising incidence and prevalence worldwide suggests that Westernisation of life style (with associated dietary and microbial cues) significantly contributes to the development and natural history of IBD. ${ }^{6}$ Specific dietary compounds that instigate or impact the

\section{Summary box}

What is already known about this subject?

- Calprotectin is an established clinical biomarker for inflammatory bowel diseases and harbours immune-regulatory functions.

What are the new findings?

- This review article summarises the extensive literature about the role of calprotectin in health and disease, covering a combination of clinical and basic research aspects.

How might it impact on clinical practice in the foreseeable future?

- Understanding the regulation and biological function of calprotectin in the gut might lead to novel diagnostic and therapeutic strategies in inflammatory bowel diseases.

\section{Key messages}

- Calprotectin concentration is an established biomarker that allows clinical decision-making in patients with suspected or confirmed inflammatory bowel disease.

- Faecal calprotectin levels correlate significantly with clinical or endoscopic disease activity in inflammatory bowel diseases.

- In health, calprotectin harbours immuneregulatory functions that are crucial for immune defence such as neutrophil chemotaxis and chelation of multiple divalent metal ions.

- In chronic inflammatory diseases calprotectin may fuel disease processes through cytokine receptor engagement and generation of reactive oxygen species.

- Better understanding of calprotectin biology in the gut may lead to novel diagnostic and therapeutic advances in inflammatory bowel diseases in future.

course of human IBD remain to be determined, while experimental studies in mice identified that nutritional compounds fuel gut inflammation partly by modulation of the intestinal microbiota. ${ }^{7-9}$

To accurately diagnose IBD, the entire spectrum of available tools should be exploited, including patient history, non-invasive and invasive imaging (endoscopy) and histological interpretation. In such a diagnostic algorithm, serum and especially faecal biomarkers help to select patients for an invasive diagnostic evaluation, ${ }^{10-12}$ in that a specific threshold allows to discriminate between functional 
(non-inflammatory) diseases with a similar clinical presentation and an inherently high prevalence (such as irritable bowel syndrome). ${ }^{13-15}$ In IBD, but also in many other inflammatory conditions, clinicians increasingly employ calprotectin (CP) as well-studied (systemic and faecal) inflammatory biomarker due to its stability, assay reproducibility and low cost to guide diagnostic and therapeutic decisions. ${ }^{16}{ }^{17}$ In contrast, the biological functions of $\mathrm{CP}$ in health and unresolved inflammation are poorly appreciated by most clinicians. In this review, we focus on emerging biological functions and clinical applications of $\mathrm{CP}$ in inflammatory diseases to facilitate interpretation in daily practice.

\section{CP IN HEALTH}

CP belongs to the family of calcium-binding S100 leucocyte proteins (with more than 24 members in vertebrates) that is evolutionary conserved and composed of two monomers in mammals (e.g. humans and mice): S100A8 and S100A9. ${ }^{18} 19$

CP was first described in the 1980s and the protein complex was discovered independently in different inflammatory conditions, which was resolved in $1988 .{ }^{20}$ Since then, the complex was termed calprotectin, emphasising the characteristic to bind $\mathrm{Ca}^{2+}$ and the antimycotic activity against Candida albicans. ${ }^{21}$

\section{Cell-specificity, transcriptional regulation and assembly}

$\mathrm{CP}$ is an abundant cytosolic protein complex (comprising S100A8 and S100A9) that is constitutively expressed in neutrophils, which represents $\sim 45 \%$ of total cytosolic protein. ${ }^{22}$ The S100A8 and S100A9 genes are located on chromosome 1 (q21) in humans ${ }^{23}$ and on chromosome 3 in mice. ${ }^{24} \mathrm{CP}$ is also constitutively expressed by monocytes, ${ }^{22}$ dendritic cells, ${ }^{25}$ activated macrophages, ${ }^{26}$ oral keratinocytes ${ }^{27}$ and squamous mucosal epithelium. ${ }^{28}$ Moreover, expression can be induced specifically during inflammation. ${ }^{29}{ }^{30}$ As such, the expression of CP in health is restricted to a very limited amount of specialised cells and may be induced during inflammation. ${ }^{31-33}$

Several cellular pathways and related transcription factors have been shown to (positively or negatively) control the expression of S100A8 and S100A9 in humans and/or mice (SPI/PU.1, SATB1, C/EBP $\alpha / \beta$, HIF-1, Arnt, GLI1, BRCA1 and AP-1). ${ }^{34}$ Conceptually, bacterial antigens and inflammatory mediators evoke expression of S100A8 and S100A9 by these transcription factors, as exemplified by the induction of $\mathrm{CP}$ expression with lipopolysaccharides (LPS), tumour necrosis factor-alpha (TNF- $\alpha$ ) and interleukin 1-beta (IL-1 $\beta$ ) in human monocytes. ${ }^{35}$ Similarly, inflammation drives CP expression in human keratinocytes. ${ }^{36}$ However, also bona-fide anti-inflammatory mediators, such as IL-10 facilitate S100A9 expression in myeloid-derived cells. ${ }^{37}$ Moreover, eosinophils may be a source of CP during gut injury and inflammation in mice. ${ }^{38}$ Notably, also nutritional deficiency and drugs may affect $\mathrm{CP}$ concentrations, as lack of zinc is described to increase $\mathrm{CP}$ levels and glucocorticoids positively regulate S100A8 expression. ${ }^{39} 40$

S100A8 and S100A9 monomers are able to form heterodimers and tetramers in $\mathrm{a} \mathrm{Ca}^{2+}$-dependent manner. ${ }^{41}$ In 2007, the crystal structure of the $\mathrm{Ca}^{2+}$-bound $\mathrm{CP}$ heterotetramer was resolved, showing transition metal-binding sites in each heterodimer. ${ }^{42}$ These sites allow binding of multiple divalent (first-row) metal ions in case of high concentrations (ie, $\mathrm{Ca}^{2+}, \mathrm{Mn}^{2+}, \mathrm{Fe}^{2+}, \mathrm{Ni}^{2+}$ and $\left.\mathrm{Zn}^{2+}\right) .{ }^{43}$ In humans, S100A8 is composed of 93 amino acids (molecular weight $10.8 \mathrm{kDa}$ ), while $\mathrm{S100A9}$ is composed of 113 amino acids (molecular weight $13.2 \mathrm{kDa}) \cdot{ }^{44} \mathrm{~S} 100 \mathrm{~A} 8$ and S100A9 consist of two $\alpha$-helix ('EF hand helix-loop-helix') motives typically allowing $\mathrm{Ca}^{2+}$-binding and $\mathrm{CP}$ complex formation. ${ }^{45} 46$ Upon $\mathrm{Ca}^{2+}$ binding, two heterodimers are able to self-associate to form a (S100A8/S100A9), heterotetramer. ${ }^{41} \mathrm{Ca}^{2+}$-dependent formation of (S100A8/S100A9) 2 tetramers is considered to be fundamental for intracellular and extracellular biological function. ${ }^{45} 47$ This may be explained by the observation that $\mathrm{Ca}^{2+}$ binding and tetramerisation promotes resistance against proteases and increases binding affinities. ${ }^{48} 49$ The mechanism underlying the release of $\mathrm{CP}$ into the extracellular space may not require the classical endoplasmic reticulum-Golgi pathway. One study suggested that CP could be released via a novel tubulin-dependent mechanism of leucocyte activation, which is controlled by protein kinase C. ${ }^{50}$ Notably, both monomers are vulnerable to oxidation on methionine and cysteine residues although functional consequences are poorly understood. ${ }^{51}$

\section{Intracellular biological functions of CP}

The S100A8/S100A9 complex controls intracellular pathways of innate immune cells and allows orchestration of an inflammatory response. ${ }^{18} \mathrm{CP}$ modulates cytoskeletal rearrangements to allow leucocyte recruitment, ${ }^{47}$ and facilitates the transport of arachidonic acid to sites of inflammation..$^{52}$ Further, nuclear S100A9/CP modifies transcription as coactivator during inflammatory processes and malignant transformations. ${ }^{53-55}$

Targeted genetic deletion indicated that mouse S100 proteins are required for transendothelial migration of phagocytes, likely by organisation of cytoskeletal metabolism and rearrangement. ${ }^{47}$ For example, microtubule polymerisation and reorganisation (which controls leucocyte migration ${ }^{56}$ ) requires the formation of the S100A8/S100A9 complex, ${ }^{45}$ which is modulated by mitogenactivated protein kinase (MAPK)-mediated S100A9 phosphorylation ${ }^{47}$ and depends on $\mathrm{Ca}^{2+}$ concentration. ${ }^{45}{ }^{57}$ In line with this, S100A9-deficient granulocytes and mice exhibit poor neutrophil recruitment during inflammation in wound healing. ${ }^{47}$ Rapid leucocyte recruitment from blood to inflammatory loci relies on a cascade of adhesion events that are triggered by selectins and $\beta 2$ integrins (CD11b/CD18). ${ }^{58} 59$ S100A8 and S100A9 control neutrophil adhesion to fibrinogen through the activation of the $\beta_{2}$ integrin Mac-1 (CD11b/CD18) ${ }^{60}$ Similarly, S100A8/S100A9 influences transendothelial migration of monocytes via increased CD11b expression. ${ }^{61}$ These findings indicate that $100 \mathrm{~A} 9$ is a regulatory subunit of the functional S100A8/S100A9 complex, which facilitates leucocyte trafficking. ${ }^{47}$

In 1997, CP was identified as a fatty acid-binding protein. ${ }^{52}$ Another study indicated that the S100A8/A9 complex is the main arachidonic acid-binding protein in human neutrophils which is $\mathrm{Ca}^{2+}$-dependent ${ }^{62}$ and appears unique to this specific S100 protein. $^{63}$ Arachidonic acid is a potent inflammatory lipid mediator as it is essential for the synthesis of leukotriene B4 that is described to favour inflammation and tissue damage during IBD ${ }^{64}$ Generally, polyunsaturated fatty acids modulate immune responses in various ways. For example, arachidonic acid derivatives fuel an inflammatory metabolite profile of innate immune cells and facilitate reactive oxygen species (ROS) production of neutrophils and potently induce cell death. ${ }^{65}$ In the context of IBD, arachidonic acid (and polyunsaturated fatty acids in general) induced production of chemokines from intestinal epithelial cells and evoked gut inflammation in genetically susceptible mice. ${ }^{9}$

It may be speculated that $\mathrm{CP}$ transports polyunsaturated fatty acids to inflammatory loci to fuel local immune responses. ${ }^{66}$

Additionally, nuclear S100A9/CP was reported to have a possible transcription coactivator function. During sepsis, 
S100A9 was described to migrate from the cytosol to the nucleus in distinct myeloid-derived suppressor cells to enhance the expression of immunosuppressive mediators. ${ }^{53}$ Nuclear S100A8/ A9 may trigger oncogenic pathways and amplify transformation in breast cancer. ${ }^{54}$ We demonstrated a relationship between the S100A8/S100A9 protein complex and complement factor C3 expression, mediating disease course in a psoriasis mouse model, as S100A9 deficiency in mice was associated with weakened psoriasis-like disease and decreased amounts of C3. S100A9 was detected in the chromatin enriched fraction in keratinocytes, modulating C3 transcription most likely through chromatin remodelling. ${ }^{55}$ Whether nuclear CP is important also in the gut and beyond remains to be demonstrated.

\section{Extracellular biological functions of CP}

The S100A8/S100A9 complex is readily secreted to allow extracellular CP functions mediated by Toll-like receptor 4 (TLR4) and receptor for advanced glycation end products (RAGE). ${ }^{67}$ However, extracellular CP can form complex protein configurations with distinct biological functions and equivalent receptors, which may not be explained by these signalling pathways. For example, CP may interact with the cluster of differentiation 36 (CD36) receptor during formation with polyunsaturated fatty acids. ${ }^{68}$ Likewise, dysregulated primary bone marrow expansion can be mediated by S100A9-induced CD33 signaling, ${ }^{69}$ and S100A9 regulates TLR2/3 cascades. ${ }^{70} 71$ Thus, the S100A8/ A9 complex activates innate immune responses and promotes inflammation likely by involvement of several receptors in a celltype and tissue specific manner.

For example, CP is described to trigger neutrophil chemotaxis and endothelial adhesion. The injection of S100A8, S100A9, or S100A8/A9 into a mouse air pouch model caused fast accumulation of neutrophils, indicating that $\mathrm{CP}$ promotes neutrophilic inflammation. ${ }^{72}$ Moreover, CP exerts antimicrobial activity which has been extensively studied. Extracellular CP complexes allow chelation of diverse transition metal ions (see above), ${ }^{43}$ which are crucial for invasive and commensal gut bacteria, as they allow bacterial enzymatic functions, cellular homeostasis and signalling cascades. ${ }^{7374}$ Numerous microbes gained the ability to overcome and escape CP-induced metal starvation through the expression of high-affinity metal transporters or metabolic alterations. $^{75} 76$ Nevertheless, S100A8/S100A9 deficiency in mice alters the intestinal microbiota, ${ }^{77}$ and mice lacking S100A9 show susceptibility to Streptococcus pneumoniae infection. ${ }^{78}$

CP also promotes the expression of pro-inflammatory and anti-inflammatory mediators. Human monocytes stimulated with S100A9 secreted IL-1 $\beta$, IL- 6 and TNF- $\alpha$ in association with oxidative stress, ${ }^{79} 80$ which was also observed in gingival fibroblasts. ${ }^{81}$ In human neutrophils, it appears that S100A9 promotes cytokine expression. ${ }^{82-84}$ CP fuels IL-1 $\beta$ secretion induced by crystals in gout which is initiated by TLR4 activation ${ }^{85}$ and overexpression of S100A8 and S100A9 in macrophages induced expression of anti-inflammatory IL- $10{ }^{86}$ In turn, an inhibition of pro-inflammatory signalling by myeloid cells is reported after S100A9 blocking. ${ }^{83}$ In mice with acute pancreatitis S100A9 gene silencing is associated with decreased release of proinflammatory cytokines. ${ }^{84}$

Besides a role for $\mathrm{CP}$ in orchestrating an acute inflammatory milieu, CP also controls cell proliferation, differentiation and apoptosis. ${ }^{87-89}$ Several studies revealed that CP, especially S100A9, modulates proliferation of tumour, epithelial and smooth muscle cells, while CP concentrations may differ significantly. $^{90-93}$ CP-induced proliferation was shown to be mediated via RAGE ligation and NF-кB activation in tumour cells, linking inflammation with tumorigenesis. ${ }^{91}$ S100A9 may also bind to TLR4 to promote MAPK signalling and monocytic cell differentiation. ${ }^{89}$ Additionally, CP plays a role in regulatory T-cell (Treg) differentiation ${ }^{94}$ that exert immunosuppressive effects and maintain self-tolerance. ${ }^{95} \mathrm{CP}$ is also described to activate natural killer (NK) cells and enhance interferon-gamma (IFN- $\gamma$ ) expression via RAGE signalling, linking inflammation with NK cell responses. ${ }^{96}$ Distinct S100A8 and S100A9 concentrations were reported to inhibit the growth of murine embryonic and human dermal fibroblasts ${ }^{97}$ and induce apoptosis of tumour cells. ${ }^{88} 97$ In human epidermal keratinocytes CP confers a survival signal at lower concentrations, while higher $(\mu \mathrm{M})$ concentrations evoked apoptosis. $^{98}$

Interestingly, a lack of S100A8/A9 in epidermal keratinocytes is associated with enhanced susceptibility for papillomas and squamous cell carcinomas. In the skin of S100A9-deficient mice elevated levels of Ki-67 were detectable during the formation of papillomas highlighting a potential regulatory function of S100A8/A9 during epidermal proliferation. ${ }^{99}$ An additional study revealed that during inflammation and malignant transformation in the skin RAGE expression on immune cells mediates S100/RAGE-driven signalling cascades, while expression on keratinocytes or endothelial cells is not required. ${ }^{100}$ We speculate that the function of each CP component depends on the expression level in specific cell types and tissues.

Collectively, these studies demonstrate that CP may shape the cellular and molecular inflammatory niche at a site of inflammation. However, CP has also been reported to maintain a chemo-repulsive effect on peripheral leukocytes i.e. movement of leukocytes away from CP. This chemorepulsive effect was reversed by oxidation of methionine at position 63 and 83 in S100A9. It may be speculated that CP function is adjusted during oxidative i.e. inflammatory conditions. ${ }^{101}$

\section{CP IN UNRESOLVED INFLAMMATION AT MUCOSAL SURFACES}

CP may initially be released by myeloid cells upon danger signalling, ${ }^{29}$ while tissue inflammation perpetuates the release of S100A8 and S100A9 by transcriptional induction in epithelial cells. ${ }^{32} 33$ The initial culprit for an inflammatory response may be an infection at the mucosal surface, a trauma or environmental stress. During unresolved inflammation, however, CP contributes to mucosal injury, inflammation and disease, for example in the skin, lung and gut. ${ }^{55} 100102-105$

In epidermal keratinocytes S100A8 and S100A9 promoted chemotaxis and psoriasis in mice. ${ }^{55} 106$ Similarly, S100A8/A9 induction during inflammatory skin disease is associated with enhanced tissue damage, reduced skin integrity and increased pro-inflammatory pathways. ${ }^{104} 106107$ Lung injury induced by influenza virus infection is partially mediated by S100A9-driven lung inflammation. ${ }^{103}$ Additionally, S100A8/A9 was shown to play a major role during tissue damage in tuberculosis. ${ }^{102}$ Vice versa, anti-S100A8 and anti-S100A9 antibodies impair migration of phagocytes to alveoli in mice by $\sim 75 \%$ in a $S$. pneumoniae model. ${ }^{108}$ In gout, S100A8 and S100A9 drive neutrophil migration initiated by monosodium urate crystals and the production of IL-1 $\beta$ fuelling joint inflammation. ${ }^{85} 109$ In gut inflammation, the biological function of CP is poorly understood. As inferred by experiments with pharmacological inhibition of S100A9 by antibody treatment, CP appears to drive dextran sodium sulfate (DSS)-induced colitis and inflammation-associated gut tumorigenesis in mice. ${ }^{105}$ In conflict with these observations, 
CP treatment protected against experimental colitis in mice induced by DSS. ${ }^{110}$ Collectively, various studies indicate that S100A9 promotes tissue inflammation at mammalian inner and outer mucosal surfaces. Recent studies indicate that CP drives inflammation beyond mucosal surfaces. For example, S100A8 and S100A9 modulate the tumour microenvironment of a broad spectrum of tumours. ${ }^{111-117}$ S100A8/A9 triggers tumorigenesis by RAGE mediated NF-kB activation at low concentration ${ }^{91}$ and mice that lack S100A9 were protected against gut tumorigenesis and inflammation. ${ }^{118}$

Most reports do not explore functional variability among the CP subunits. S100A8 and S100A9 are considered to function mainly synergistically. Especially, S100A8 was described to rely on S100A9, as in vivo studies implicated that S100A8 is unstable without S100A9. ${ }^{119}$ For a long period, S100A9 knockout mice were described to lack S100A8 protein as well. However, constitutively active S100A8 homodimers were reported to be present during TNF- $\alpha$ signalling in the absence of S100A9. ${ }^{120}$ Interestingly, mice lacking S100A9 are viable and healthy, ${ }^{119}{ }^{121}$ while the disruption of S100A8 in mice is associated with lethality during embryo development. ${ }^{122}$ This outcome revealed a previously unknown function of S100A8 in early embryonic preimplantation phase and S100A8 was shown to be important for placenta maturation. ${ }^{123}$ For more than two decades the disruption of the S100A8 gene in mice was reported to be lethal during embryogenesis. However, recently Cesaro et al published the first viable and fertile S100A8-deficient mice. ${ }^{124} 125$ Future studies with conditional S100A8 alleles will be essential to explain this discrepancy. Collectively, the biological function of the S100A8 subunit may be opposed to that of S100A9 in tissue inflammation. For example, S100A8 diminished mast cell degranulation, the expression of pro-inflammatory mediators and eosinophil infiltration during acute asthma in mice. ${ }^{126}$

Interestingly, distinct CP subunit configurations were shown to trigger different cellular pathways especially in the context of inflammation and tumorigenesis. ${ }^{120127128}$ S100A8 and S100A9 usually organise as heterodimeric complexes that form heterotetramers in case of calcium availability. ${ }^{41}$ Recently, homodimeric complexes were reported to play a crucial role in various inflammatory conditions. Active S100A9 homodimers were found in the spleen of mice with present inflammation or after tumour inoculation. ${ }^{127}$ It might be speculated that distinct CP subunit configurations may be responsible for the amplification and maintenance of inflammatory processes. ${ }^{120} 128$ Recently, Vogl et al revealed that tetramer formation may limit local inflammatory properties of both subunits, as S100A8/S100A9 is only transiently active in the extracellular environment, since calciumdependent tetramerisation of S100A8/S100A9 may lead to an autoinhibition of both subunits. In contrast, homodimers were shown to constitutively trigger inflammatory pathways through TLR4 activation. ${ }^{120}$ However, the exact molecular functions of the individual protein configurations remain unclear.

\section{FAECAL CP IN HEALTH AND DISEASE}

Faecal CP concentrations found in healthy individuals somewhat range between $\sim 10$ and $50 \mu \mathrm{g} / \mathrm{g}$ stool which depends on study cohorts and the used assay. ${ }^{129-131}$

However, various studies proved that faecal CP concentrations are physiologically elevated in infants younger than 4 years when compared with adults. ${ }^{132}$ A recent study reported that faecal concentration of S100A8 and S100A9 are physiologically higher in healthy term neonates after vaginal delivery compared with caesarean section. Labor-associated stress was determined as the decisive factor leading to elevated CP concentration after secondary caesarean section and vaginal delivery. ${ }^{77}$ Additionally, high levels of S100A8 and S100A9 are contained in breast milk, indicating a role for $\mathrm{CP}$ in shaping the immune system of newborns. ${ }^{133}$ Indeed, Willers et al demonstrated that S100A8 and S100A9 regulate programming of intestinal immunity and high faecal CP levels are associated with intestinal colonisation by a favourable microbiota in neonates. ${ }^{77}$ As a result, CP concentrations in paediatric patients should be interpreted with caution. ${ }^{134}$

\section{Faecal CP as biomarker of inflammatory diseases in the gut}

Before the possibility to detect CP in the stool in $1992,{ }^{135}$ clinicians relied on serological markers to assess the possibility (or severity) of gut inflammation. However, erythrocyte sedimentation rate and serum C-reactive protein (CRP) are elevated in response to various non-inflammatory processes and poorly correlate with patient symptoms and intestinal disease activity. ${ }^{136}$ In contrast, faecal CP is able to discriminate between noninflammatory and inflammatory disease of the intestine, ${ }^{13} 14$ can be retrieved non-invasively, is inexpensive and remains stable at room temperature in stool for at least 3 days (with 30\% inadequacy after 7 days). ${ }^{137}$ Notably, studies indicated that faecal $\mathrm{CP}$ represents a more sensitive marker than CRP in the context of IBDs, while it remains unclear if the combination of these biomarkers improves diagnostic accuracy. ${ }^{138} 139$ These features make faecal CP an excellent (i.e. sensitive) biomarker to detect gut inflammation in IBD-which may be some reasons for its worldwide use today. In contrast, specificity of this biomarker is relatively low, opening a range of differential diagnoses.

Considering the plethora of biological functions of CP in health and disease, high sensitivity but low specificity of faecal CP to detect gut inflammation may not be surprising. Faecal CP correlates with the number of neutrophils present in the intestinal lumen and thus allows to detect an acute inflammatory response in the gut, ${ }^{140}{ }^{141}$ but faecal CP does not allow to discriminate distinct aetiologies. For example, human faecal CP concentrations are substantially elevated during Salmonella infection (median of $765 \mu \mathrm{g} / \mathrm{g}$ ), Campylobacter infection (median of $689 \mu \mathrm{g} / \mathrm{g}$ ) or Clostridioides difficile infection (median of $740 \mu \mathrm{g} / \mathrm{g}$ ) and correlate with disease severity. ${ }^{142-144}$ In contrast, viral infections for example, rotavirus or norovirus are usually present with lower (but elevated) concentrations $(\sim 90 \mu \mathrm{g} / \mathrm{g})$ when compared with healthy controls. Notably, most data on faecal CP levels during GI infections are based on paediatric patients. ${ }^{142}$ Likewise, elevated faecal CP concentrations were reported for HIV infection (regardless of antiretroviral therapy status) ${ }^{145}$ and corona virus disease 2019 induced by SARS-CoV2 infection. ${ }^{146}$ Further, also intestinal malignancies are associated with increased faecal CP concentration as observed for example in colorectal cancer, probably because of a local inflammatory response. ${ }^{147}$ Typically, chronic inflammatory diseases of the gut also demonstrate increased faecal CP concentrations, partly because neutrophilic inflammation is an aspect of the disease ${ }^{141}$ and partly because gut inflammation may induce intestinal epithelial CP expression (figure 1). ${ }^{32} 33148$ Faecal CP is elevated (and correlates with disease activity) in IBD, ${ }^{149-153}$ in necrotising enterocolitis, ${ }^{154}$ graft-versus-host disease, ${ }^{155}$ and drug-induced enteropathy (e.g. non-steroidal anti-inflammatory drugs (NSAIDs)). ${ }^{156}$ Diagnostic precision to detect gut inflammation in the lower GI tract is better when compared with the upper GI tract. ${ }^{157}$ A study which included patients with IBD (and patients with 


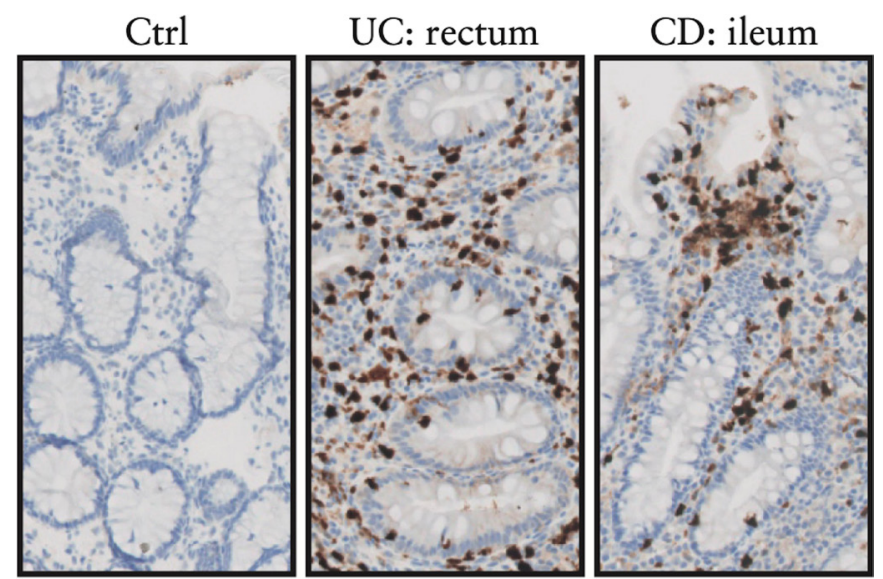

Figure 1 Calprotectin expression in the gut, adapted from reference 148. Mucosal calprotectin expression indicated by brown immunohistochemical staining is visualised in lamina propria immune cells and to a lesser extent the intestinal epithelium in ulcerative colitis (UC) and Crohn's disease (CD), but not healthy controls (Ctrl).

GI malignancies) undergoing colonoscopy indicated that bowel preparation and upper or lower endoscopy did not affect faecal CP concentration after the procedure. ${ }^{158}$

Collectively, faecal CP can be used to virtually exclude a wide range of intestinal diseases characterised by gut inflammation, while it does not allow to discriminate potential triggers. As such, other causes of elevated faecal CP concentration must be ruled out prior to IBD diagnosis. Strongly elevated faecal CP concentration is frequently observed during bacterial infections. Interpretation of slightly elevated faecal CP concentrations should be made with care, as viral infections and drugs (e.g. NSAIDs, ${ }^{156}$ proton pump inhibitors, ${ }^{159}$ glucocorticoids, ${ }^{40}$ and levodopa ${ }^{160}$ ) may induce S100A8 and/or S100A9 expression, and GI bleeding is associated with moderately elevated CP levels (i.e. $50-200 \mu \mathrm{g} / \mathrm{g}$ ). ${ }^{161}$

\section{Faecal CP discriminates between inflammatory and non- inflammatory gut disease}

Although faecal CP values $>600 \mu \mathrm{g} / \mathrm{g}$ are strongly associated with IBD (or food-borne infections), no consistent CP cut-off is established that would allow to diagnose IBD with high accuracy. ${ }^{162}$ Thus, clinicians rely on probabilities to rule in or to rule out IBD (or functional gut diseases) based on faecal CP concentration. The threshold of what is considered an 'elevated' faecal CP (or vice versa what is considered healthy) is still debated. As already mentioned earlier, faecal CP concentrations found in healthy individuals mainly range between $\sim 10-50 \mu \mathrm{g} / \mathrm{g}$ stool, which depends on study cohorts and the used assay. ${ }^{129-131} \mathrm{~A}$ meta-analysis including 12 studies (comprising 491 healthy controls, 595 patients with IBS and 1059 patients with IBD) generally indicated that faecal CP concentrations of $\leq 40 \mu \mathrm{g} / \mathrm{g}$ (using sensitive assays) rule out IBD (i.e. provides $\leq 1 \%$ probability of having IBD). ${ }^{14}$ Several studies implicated that faecal CP allowed differentiation between non-IBD and IBD at a cut-off between 100-200 $\mu \mathrm{g} / \mathrm{g} .{ }^{14149} 163164$ However, an exact faecal CP cut-off value for the discrimination between IBD and functional bowel diseases is not established. ${ }^{11}$ Clinical decision-making to discriminate inflammatory from non-inflammatory disease with relative accuracy and the need for endoscopy is indicated in figure $2 \mathrm{~A}$.

\section{Faecal CP allows evaluation of IBD course}

Most clinical studies indicate a strong correlation between faecal CP concentration and clinical or endoscopic disease activity. ${ }^{150152165166}$ For example, one study associated faecal CP concentrations, i.e. grade $0(\leq 16(10-30) \mu \mathrm{g} / \mathrm{g})$, grade 1 $(\sim 35(25-48) \mu \mathrm{g} / \mathrm{g})$, grade $2(\sim 102(44-159 \mu \mathrm{g} / \mathrm{g})$, grade 3 $(\sim 235(176-319) \mu \mathrm{g} / \mathrm{g})$ and grade $4(\sim 611(406-868) \mu \mathrm{g} / \mathrm{g})$, with endoscopic UC activity. ${ }^{167}$ Zollner et al compared clinical and endoscopic activity-related correlations between faecal CP and faecal lipocalin-2 in a cohort of 132 patients (72 patients with CD, 40 controls) and confirmed the diagnostic equivalence of both biomarkers in IBD. Analysis by confocal microscopy and immunocytochemistry implicated strong expression of CP in granulocytes, macrophages and to a lesser extent the intestinal epithelium in patients with IBD (see also figure 1). ${ }^{148}$ Data generally indicate that faecal CP is significantly decreased in patients with clinical and endoscopic remission and that values of $>150 \mu \mathrm{g} / \mathrm{g}$ are mainly associated with disease relapse. ${ }^{168-170}$ However, other studies reported higher cut-off values of $>200-300 \mu \mathrm{g} / \mathrm{g}$ to implicate disease relapse. ${ }^{171-173}$ Recently published Selecting Therapeutic Targets in Inflammatory Bowel Disease (STRIDE-II) recommendations by the International Organization for the Study of Inflammatory Bowel Diseases (IOIBD) announced faecal CP values of $<150 \mu \mathrm{g} / \mathrm{g}$ as goal reflecting remission, stating that faecal CP values ranging from 150 to $250 \mu \mathrm{g} / \mathrm{g}$ are a grey zone. ${ }^{174}$ In contrast, a patient population from China demonstrates a cut-off of $50 \mu \mathrm{g} / \mathrm{g}$ to be suitable for the differentiation between active and inactive UC, ${ }^{153}$ such that studies suggest different cut-off values for active disease which may be explained by the definition of remission, assay variability and ethnic differences of faecal CP concentration. ${ }^{129-131}$ Prior to clinically based diagnosis of a flare, faecal CP is reported to be elevated $\sim 8$ weeks in advance. In contrast, patients who maintain remission usually present faecal CP concentrations of $<60 \mu \mathrm{g} / \mathrm{g} .{ }^{175} 176$ Notably, Theede et al reported that faecal CP evaluation is sufficient to determine risk of relapse 6 and 12 months in advance and to evaluate mucosal healing in UC. ${ }^{177}$ Based on a plethora of studies, clinical decision-making in IBD is indicated in figure 2B. Faecal CP is also used as biomarker to identify postoperative disease recurrence in adult ${ }^{178}$ and paediatric patients with IBD. ${ }^{179}$ A meta-analysis including nine studies indicated that a faecal CP cut-off of $>150 \mu \mathrm{g} / \mathrm{g}$ is likely to have the best overall accuracy to predict postoperative endoscopic recurrence with a sensitivity of $\sim 70 \% .{ }^{180}$ Notably, current recommendations suggest endoscopy (rather than sole biomarker screening) to detect postoperative disease recurrence. Clinical trials are necessary to establish faecal CP (rather than endoscopy) to guide therapeutic decisions and to establish treatment algorithms postoperatively. Only then, clinical guidelines may recommend specific faecal CP concentrations to indicate disease activity and the requirement for therapeutic intervention, which is currently being avoided. ${ }^{181} 182$

\section{SERUM CP AS BIOMARKER OF INFLAMMATORY DISEASES IN AND BEYOND THE GUT}

Recently, serum CP has gained attention as a potential biomarker for the evaluation of IBD and other inflammatory diseases with heterogeneous results. For example, one study comprising 156 patients (82 IBD and 74 non-IBD) suggested that serum CP may represent a promising marker for the assessment of inflammatory status and disease course ${ }^{183}$ and further studies confirmed the observation in adult and paediatric patients with IBD. ${ }^{184} 185$ 


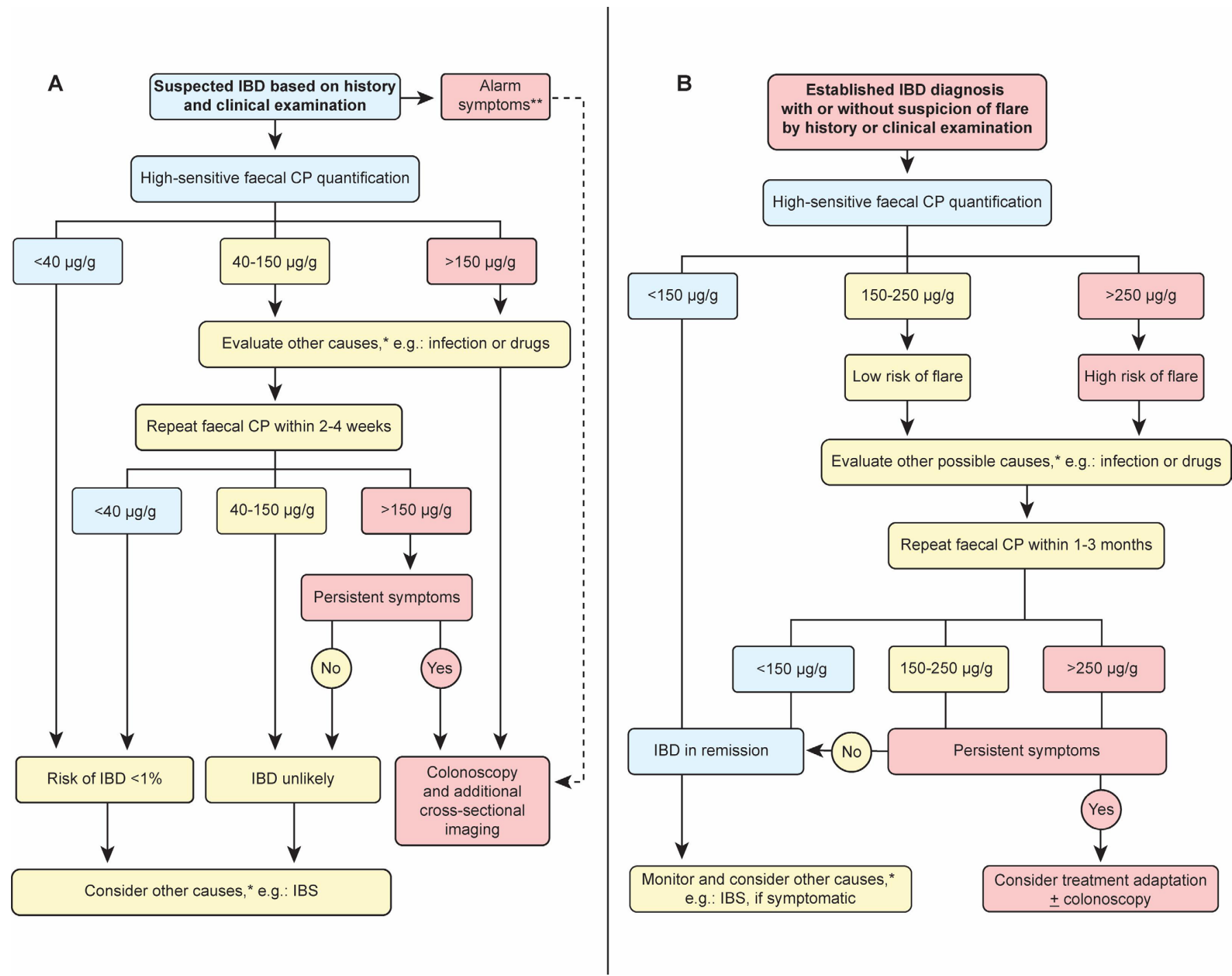

Figure 2 Proposed algorithm for the interpretation of faecal calprotectin (CP) concentration. No evidence-based algorithm has been established by controlled clinical trials. This algorithm is based on literature research and clinical experience. Note that faecal CP concentration reflects only one aspect of disease evaluation and should always be interpreted in conjunction with history and clinical and/or endoscopic examination. Panel A: In suspected inflammatory bowel diseases (IBD) (e.g. Gl symptoms such as diarrhoea, bleeding or abdominal pain $>4$ weeks), faecal CP and a stool (pathogen) culture should be obtained. Repeated elevated faecal CP concentration (>40 $\mu \mathrm{g} / \mathrm{g}$ ) or persistent symptoms require further investigations. Faecal CP is also elevated during gastroenteritis (viral and bacterial), diverticular disease, drug-induced enteropathy and intestinal malignancies. IBS may also present with elevated CP but its probability decreases with higher concentrations ( $>150 \mu \mathrm{g} / \mathrm{g})$. Panel B: In patients with an established diagnosis of IBD, faecal CP supports the diagnosis of active disease or remission. Faecal CP concentration $<150 \mu \mathrm{g} / \mathrm{g}$ usually indicates remission with high accuracy. Elevated faecal CP concentration $(>150 \mu \mathrm{g} / \mathrm{g})$ raises suspicion for disease activity as elevated CP concentration is associated with increased risk of a clinically apparent disease flare in the following months. Based on the recently published Selecting Therapeutic Targets in Inflammatory Bowel Disease-II (STRIDE-II) recommendations values of 150-250 $\mu \mathrm{g} / \mathrm{g}$ are considered as grey zone. ${ }^{174}$ In symptomatic patients with IBD, other causes for elevated faecal CP should be excluded (such as infection and drug-induced enteropathy) and endoscopy should be performed before switching medical therapy. ${ }^{*}$ In immunocompromised patients, serological testing for cytomegalovirus (CMV), HIV and herpes simplex virus (HSV) may be obtained and history should exclude drug-induced enteropathy associated with non-steroidal anti-inflammatory drugs, proton-pump inhibitors, sartans, levodopa and rarely other drugs. * *Alarm symptoms are defined by unintentional weight loss, night sweat, bloody diarrhoea and/ or vomiting indicating upper and/or lower endoscopy.

Likewise, several inflammatory diseases beyond the gut display elevated serum and/or tissue CP concentrations, as observed in psoriasis, ${ }^{186}$ rheumatoid arthritis, ${ }^{187}$ systemic lupus erythematosus, ${ }^{188}$ ankylosing spondyloarthritis, ${ }^{189}$ periodontitis, ${ }^{190}$ and human malignancies (e.g. myelodysplastic syndrome, ${ }^{111}$ head and neck squamous cell carcinoma, ${ }^{191}$ bladder cancer, ${ }^{112}$ nonsmall cell lung cancer, ${ }^{113}$ breast cancer, ${ }^{114}$ pancreatic cancer, ${ }^{115}$ prostate cancer ${ }^{116}$ and hepatocellular carcinoma ${ }^{117}$ ). Interestingly, systemic inflammation is detectable through serum CP in the majority of patients with psoriatic disease especially with joint manifestation, even in case of low CRP levels, highlighting high diagnostic sensitivity of CP. ${ }^{192}$ However, systemic low grade inflammation, as observed in type II diabetes and obesity, is also linked with elevated blood CP concentration, ${ }^{193-195}$ which could be a significant confounder in CP studies beyond metabolic diseases.

Recently, plasma and serum CP concentrations were implicated as valuable prognostic biomarkers for the assessment 


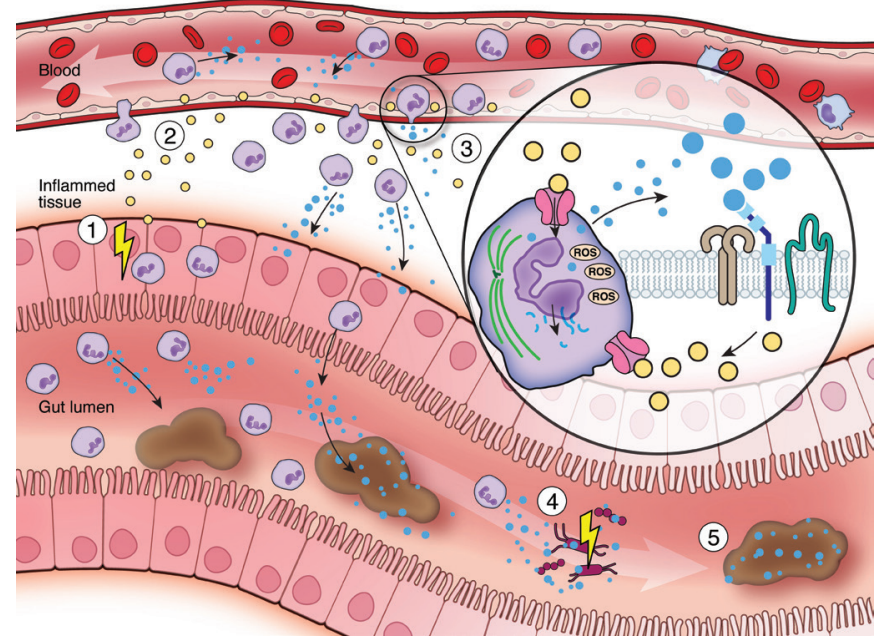

Figure 3 Calprotectin in the control of gut inflammation. (1) Inflammatory bowel diseases arise from a disrupted host-microbe interplay resulting in chronic remittent gut inflammation. (2) Tissue inflammation is driven by cytokines (yellow) activating innate and adaptive immunity. (3) Acute inflammation leads to the mucosal recruitment of neutrophil granulocytes (violet) which partly migrate into the gut lumen. Neutrophils constitutively express and release calprotectin (blue) which may fuel mucosal inflammation, as calprotectin drives neutrophil chemotaxis, induces the expression of endothelial adhesion molecules and activates pattern recognition receptors (e.g. Toll-like receptor 4 or receptor for advanced glycation end products) on innate and adaptive immune cells. Calprotectin in neutrophils modulates tissue adherence by microtubule rearrangements (green) and cytotoxicity by generation of reactive oxygen species via NADPH oxidase. (4) Calprotectin also harbours antimicrobial functions. Calprotectin allows chelation of essential divalent metal ions (e.g. calcium, iron or zinc) limiting growth of invasive and commensal gut bacteria. (5) Calprotectin represents a well-studied non-invasive (systemic and faecal) inflammatory biomarker in inflammatory bowel diseases due to its stability at room temperature, assay reproducibility and low costs. However, faecal calprotectin is also elevated during gut infection, other gastrointestinal diseases and in drug-induced enteropathy. ROS, reactive oxygen species.

of disease course and outcome in hospitalised patients with COVID-19, reflecting current and future disease severity. ${ }^{196}$ In Klebsiella pneumoniae sepsis patients displayed increased serum CP concentrations which predicted 28-day mortality. ${ }^{197}$ Collectively, these studies indicate the potential of CP to guide management (and potentially therapy) in many clinical scenarios, a concept that warrants disease-specific trials.

\section{CONCLUSION}

Major advances over the last decade have fostered our understanding of the molecular functions of CP in mammals. Translation of biological insights by mechanistic studies of mucosal surfaces in mice to human disease is scarce, but would evolve our understanding of $\mathrm{CP}$ as inflammatory biomarker. Both subunits, S100A8 and S100A9, harbour a broad spectrum of intracellular and extracellular immunomodulatory properties (figure 3)..$^{18476772}$ However, it is still debated whether the biological function of the S100A8 subunit may be opposed to that of S100A9 in tissue inflammation and tumorigenesis. Analysis of tissue-specific knock-out mice of either subunit and/or blocking distinct binding sites will help to delineate divergent intracellular or extracellular biological functions. Considering the transcriptional regulation and biological functions of $\mathrm{CP}$ during inflammation, clinicians should be aware that other conditions, most commonly GI (bacterial or viral) infections, but also malignancies, drugs and graft-versus-host disease, are paralleled by increased faecal CP concentrations. Faecal CP represents an extensively validated biomarker for the diagnosis and longitudinal evaluation of IBD reflecting endoscopic disease activity reasonably well. Lack of guidelines and data regarding optimal faecal CP cut-offs renders intermediate faecal CP concentrations of $150-250 \mu \mathrm{g} / \mathrm{g}$ (declared as grey zone by STRIDE-II recommendations ${ }^{174}$ ) frequently challenging to interpret in IBD, while $<40 \mu \mathrm{g} / \mathrm{g}$ rules out IBD and $>250 \mu \mathrm{g} / \mathrm{g}$ should prompt evaluation for IBD or raise suspicion for an IBD flare (figure 2). ${ }^{14} 149167$ We propose that a better understanding of the biological functions of CP and particularly the S100A8 and S100A9 subunits will lead to novel diagnostic and therapeutic advances in humans in the future.

\section{Contributors All authors contributed equally.}

Funding We are grateful for the support received from the Austrian Science Fund (FWF P33070) (to T.E.A.). We thank the Excellence Initiative (Competence Centers for Excellent Technologies-COMET) of the Austrian Research Promotion Agency FFG: Research Center of Excellence in Vascular Ageing Tyrol, VASCage (K-Project Nr. 843536) funded by BMVIT, BMWFW, Wirtschaftsagentur Wien and Standortagentur Tirol for their financial support (to H.T.).

Competing interests None declared.

Patient consent for publication Not required.

Provenance and peer review Not commissioned; externally peer reviewed.

Open access This is an open access article distributed in accordance with the Creative Commons Attribution Non Commercial (CC BY-NC 4.0) license, which permits others to distribute, remix, adapt, build upon this work non-commercially, and license their derivative works on different terms, provided the original work is properly cited, appropriate credit is given, any changes made indicated, and the use is non-commercial. See: http://creativecommons.org/licenses/by-nc/4.0/.

\section{ORCID iDs}

Almina Jukic http://orcid.org/0000-0001-8201-1376

Herbert Tilg http://orcid.org/0000-0002-4235-2579

\section{REFERENCES}

1 Kotas ME, Medzhitov R. Homeostasis, inflammation, and disease susceptibility. Cell 2015; 160:816-27.

2 Netea MG, Balkwill F, Chonchol M, et al. A guiding map for inflammation. Nat Immunol 2017:18:826-31.

3 Harbord M, Annese V, Vavricka SR, et al. The first European evidence-based consensus on extra-intestinal manifestations in inflammatory bowel disease. J Crohns Colitis 2016;10:239-54

4 Thia KT, Loftus EV, Sandborn WJ, et al. An update on the epidemiology of inflammatory bowel disease in Asia. Am J Gastroenterol 2008;103:3167-82.

5 Tsironi E, Feakins RM, Probert CSJ, et al. Incidence of inflammatory bowel disease is rising and abdominal tuberculosis is falling in Bangladeshis in East London, United Kingdom. Am J Gastroenterol 2004;99:1749-55.

6 GBD 2017 Inflammatory Bowel Disease Collaborators. The global, regional, and national burden of inflammatory bowel disease in 195 countries and territories, 1990-2017: a systematic analysis for the global burden of disease study 2017. Lancet Gastroenterol Hepatol 2020;5:17-30.

7 Devkota S, Wang Y, Musch MW, et al. Dietary-fat-induced taurocholic acid promotes pathobiont expansion and colitis in IL10-/- mice. Nature 2012;487:104-8.

8 Chassaing B, Koren 0, Goodrich JK, et al. Dietary emulsifiers impact the mouse gut microbiota promoting colitis and metabolic syndrome. Nature 2015;519:92-6

9 Mayr L, Grabherr F, Schwärzler J, et al. Dietary lipids fuel GPX4-restricted enteritis resembling Crohn's disease. Nat Commun 2020;11:1775.

10 van Rheenen PF, Van de Vijver E, Fidler V. Faecal calprotectin for screening of patients with suspected inflammatory bowel disease: diagnostic meta-analysis. BMJ 2010;341:c3369.

11 Maaser C, Sturm A, Vavricka SR, et al. ECCO-ESGAR guideline for diagnostic assessment in IBD Part 1: initial diagnosis, monitoring of known IBD, detection of complications. Journal of Crohn's colitis 2019;13:144-64.

12 Khalil H, Sherwood P. PTH-034 Do faecal calprotectin levels influence colonoscopy rates? Gut 2018;67:A29. 
13 Schoepfer AM, Trummler M, Seeholzer P, et al. Discriminating IBD from IBS: comparison of the test performance of fecal markers, blood leukocytes, CRP, and IBD antibodies. Inflamm Bowel Dis 2008;14:32-9.

14 Menees SB, Powell C, Kurlander J, et al. A meta-analysis of the utility of C-reactive protein, erythrocyte sedimentation rate, fecal calprotectin, and fecal lactoferrin to exclude inflammatory bowel disease in adults with IBS. Am J Gastroenterol 2015;110:444-54.

15 Rouke JO, Dhaliwal A, Sagar V, et al. PTU-061 Use of faecal calprotectin in primary care to distinguish irritable bowel syndrome from inflammatory bowel disease: Abstract PTU-061 Table 1. Gut 2015;64:A86.2-7.

16 Sands BE. Biomarkers of inflammation in inflammatory bowel disease. Gastroenterology 2015;149:1275-85.

17 Ometto F, Friso L, Astorri $\mathrm{D}$, et al. Calprotectin in rheumatic diseases. Exp Biol Med 2017;242:859-73.

18 Donato R, R. Cannon B, Sorci G, et al. Functions of S100 proteins. Curr Mol Med 2013;13:24-57.

19 Zimmer DB, Eubanks JO, Ramakrishnan D, et al. Evolution of the S100 family of calcium sensor proteins. Cell Calcium 2013;53:170-9.

20 Andersson KB, Sletten K, Berntzen HB, et al. The leucocyte L1 protein: identity with the cystic fibrosis antigen and the calcium-binding MRP-8 and MRP-14 macrophage components. Scand J Immunol 1988;28:241-5.

21 Steinbakk M, Naess-Andresen CF, Lingaas E, et al. Antimicrobial actions of calcium binding leucocyte L1 protein, calprotectin. Lancet 1990;336:763-5.

22 Edgeworth J, Gorman M, Bennett R, et al. Identification of p8,14 as a highly abundant heterodimeric calcium binding protein complex of myeloid cells. J Biol Chem 1991;266:7706-13.

23 Schäfer BW, Wicki R, Engelkamp D, et al. Isolation of a YAC clone covering a cluster of nine $\mathrm{S} 100$ genes on human chromosome 1q21: rationale for a new nomenclature of the $\$ 100$ calcium-binding protein family. Genomics 1995;25:638-43

24 Dorin JR, Emslie E, van Heyningen V. Related calcium-binding proteins map to the same subregion of chromosome $1 q$ and to an extended region of synteny on mouse chromosome 3. Genomics 1990;8:420-6.

25 Kumar A, Steinkasserer A, Berchtold S. Interleukin-10 influences the expression of MRP8 and MRP14 in human dendritic cells. Int Arch Allergy Immunol 2003;132:40-7.

26 Odink K, Cerletti N, Brüggen J, et al. Two calcium-binding proteins in infiltrate macrophages of rheumatoid arthritis. Nature 1987;330:80-2.

27 Eversole LR, Miyasaki KT, Christensen RE. The distribution of the antimicrobial protein, calprotectin, in normal oral keratinocytes. Arch Oral Biol 1992;37:963-8.

28 Wilkinson MM, Busuttil A, Hayward C, et al. Expression pattern of two related cystic fibrosis-associated calcium-binding proteins in normal and abnormal tissues. J Cell Sci 1988:91 (Pt 2):221-30.

29 Xu K, Geczy CL. Ifn-Gamma and TNF regulate macrophage expression of the chemotactic S100 protein S100A8. J Immunol 2000;164:4916-23.

30 Hu SP, Harrison C, Xu K, et al. Induction of the chemotactic S100 protein, CP-10, in monocyte/macrophages by lipopolysaccharide. Blood 1996;87:3919-28.

31 Kunz M, Roth J, Sorg C, et al. Epidermal expression of the calcium binding surface antigen 27E10 in inflammatory skin diseases. Arch Dermatol Res 1992;284:386-90.

32 Lügering N, Stoll R, Kucharzik T, et al. Immunohistochemical Distribution and Serum Levels of the $\mathrm{Ca}(2+)$-Binding Proteins MRP8, MRP14 and Their Heterodimeric Form MRP8/14 in Crohn's Disease. Digestion 1995;56:406-14.

33 Schmid KW, Lügering N, Stoll R. Immunohistochemical demonstration of the calcium-binding proteins MRP8 and MRP14 and their heterodimer (27E10 antigen) in Crohn's disease. Hum Pathol 1995:26:334-7.

34 Swindell WR, Johnston A, Xing X. Robust shifts in S100A9 expression with aging: a novel mechanism for chronic inflammation. Sci Rep 2013:3:1215.

35 Suryono KJI, Hayashi N, et al. Calprotectin expression in human monocytes: induction by Porphyromonas gingivalis lipopolysaccharide, tumor necrosis factor- $\alpha$, and interleukin-1ß. J Periodontol 2005;76:437-42.

36 Mørk G, Schjerven H, Mangschau L, et al. Proinflammatory cytokines upregulate expression of calprotectin (L1 protein, MRP-8/MRP-14) in cultured human keratinocytes. Br J Dermatol 2003;149:484-91.

37 Bah I, Kumbhare A, Nguyen L, et al. II-10 induces an immune repressor pathway in sepsis by promoting S100A9 nuclear localization and MDSC development. Cell Immunol 2018;332:32-8.

38 Reichman H, Moshkovits I, Itan M, et al. Transcriptome profiling of mouse colonic eosinophils reveals a key role for eosinophils in the induction of \$100A8 and S100A9 in mucosal healing. Sci Rep 2017;7:7117.

39 Lienau S, Rink L, Wessels I. The role of zinc in calprotectin expression in human myeloid cells. J Trace Elem Med Biol 2018;49:106-12.

40 Hsu K, Passey RJ, Endoh Y, et al. Regulation of S100A8 by glucocorticoids. J Immunol 2005; 174:2318-26

41 Vogl T, Roth J, Sorg C, et al. Calcium-Induced noncovalently linked tetramers of MRP8 and MRP14 detected by ultraviolet matrix-assisted laser desorption/ionization mass spectrometry. J Am Soc Mass Spectrom 1999;10:1124-30.

42 Korndörfer IP, Brueckner F, Skerra A. The crystal structure of the human (S100A8/ S100A9)2 heterotetramer, calprotectin, illustrates how conformational changes of interacting alpha-helices can determine specific association of two EF-hand proteins. J Mol Biol 2007:370:887-98.

43 Zygiel EM, Nolan EM. Transition metal sequestration by the host-defense protein calprotectin. Annu Rev Biochem 2018;87:621-43.

44 Hunter MJ, Chazin WJ. High level expression and dimer characterization of the $\$ 100$ EF-hand proteins, migration inhibitory factor-related proteins 8 and 14. J Biol Chem 1998;273:12427-35.

45 Leukert N, Vogl T, Strupat K, et al. Calcium-Dependent tetramer formation of S100A8 and S100A9 is essential for biological activity. J Mol Biol 2006;359:961-72.

46 Vogl T, Gharibyan AL, Morozova-Roche LA. Pro-Inflammatory S100A8 and S100A9 proteins: self-assembly into multifunctional native and amyloid complexes. Int J Mol Sci 2012;13:2893-917.

47 Vogl T, Ludwig S, Goebeler M, et al. Mrp8 and MRP14 control microtubule reorganization during transendothelial migration of phagocytes. Blood 2004;104:4260-8.

48 Stephan JR, Nolan EM. Calcium-Induced tetramerization and zinc chelation shield human calprotectin from degradation by host and bacterial extracellular proteases. Chem Sci 2016;7:1962-75.

49 Brophy MB, Hayden JA, Nolan EM. Calcium ion gradients modulate the zinc affinity and antibacterial activity of human calprotectin. J Am Chem Soc 2012;134:18089-100

50 Rammes A, Roth J, Goebeler M, et al. Myeloid-Related protein (MRP) 8 and MRP14, calcium-binding proteins of the $\mathrm{S} 100$ family, are secreted by activated monocytes via a novel, tubulin-dependent pathway. J Biol Chem 1997;272:9496-502.

51 Sroussi HY, Köhler GA, Agabian N, et al. Substitution of methionine 63 or 83 in S100A9 and cysteine 42 in S100A8 abrogate the antifungal activities of S100A8/A9: potential role for oxidative regulation. FEMS Immunol Med Microbiol 2009:55:55-61.

52 Klempt M, Melkonyan H, Nacken W, et al. The heterodimer of the Ca2+-binding proteins MRP8 and MRP14 binds to arachidonic acid. FEBS Lett 1997;408:81-4

53 Dai J, Kumbhare A, Youssef D, et al. Intracellular S100A9 promotes myeloid-derived suppressor cells during late sepsis. Front Immunol 2017;8:1565.

54 Song R, Struhl K. S100A8/S100A9 cytokine acts as a transcriptional coactivator during breast cellular transformation. Sci Adv 2021;7. doi:10.1126/sciadv.abe5357. [Epub ahead of print: 0101 2021].

55 Schonthaler HB, Guinea-Viniegra J, Wculek SK, et al. S100A8-S100A9 protein complex mediates psoriasis by regulating the expression of complement factor C3. Immunity 2013;39:1171-81.

56 Pettit EJ, Fay FS. Cytosolic free calcium and the cytoskeleton in the control of leukocyte chemotaxis. Physiol Rev 1998;78:949-67.

57 Roth J, Burwinkel F, van den Bos C, et al. Mrp8 and MRP14, S-100-like proteins associated with myeloid differentiation, are translocated to plasma membrane and intermediate filaments in a calcium-dependent manner. Blood 1993:82:1875-83.

58 Springer TA. Traffic signals for lymphocyte recirculation and leukocyte emigration: the multistep paradigm. Cell 1994;76:301-14.

59 Parkos CA, Delp C, Arnaout MA, et al. Neutrophil migration across a cultured intestinal epithelium. Dependence on a CD11b/CD18-mediated event and enhanced efficiency in physiological direction. J Clin Invest 1991;88:1605-12.

60 Newton RA, Hogg N. The human $\$ 100$ protein MRP-14 is a novel activator of the beta 2 integrin Mac-1 on neutrophils. J Immunol 1998;160:1427-35.

61 Eue I, Pietz B, Storck J, et al. Transendothelial migration of 27E10+ human monocytes. Int Immunol 2000;12:1593-604.

62 Kerkhoff C, Klempt M, Kaever V, et al. The two calcium-binding proteins, S100A8 and S100A9, are involved in the metabolism of arachidonic acid in human neutrophils. J Biol Chem 1999:274:32672-9.

63 Sopalla C, Leukert N, Sorg C, et al. Evidence for the involvement of the unique C-tail of S100A9 in the binding of arachidonic acid to the heterocomplex S100A8/A9. Biol Chem 2002;383:1895-905.

64 Nielsen $\mathrm{OH}$, Ahnfelt-Rønne I, Elmgreen J. Abnormal metabolism of arachidonic acid in chronic inflammatory bowel disease: enhanced release of leucotriene B4 from activated neutrophils. Gut 1987:28:181-5

65 Tallima H, El Ridi R. Arachidonic acid: Physiological roles and potential health benefits - A review. J Adv Res 2018;11:33-41.

66 Kerkhoff C, Vogl T, Nacken W, et al. Zinc binding reverses the calcium-induced arachidonic acid-binding capacity of the S100A8/A9 protein complex. FEBS Lett 1999:460:134-8.

67 Ma L, Sun P, Zhang J-C, et al. Proinflammatory effects of S100A8/A9 via TLR4 and RAGE signaling pathways in BV-2 microglial cells. Int J Mol Med 2017:40:31-8.

68 Kerkhoff C, Sorg C, Tandon NN, et al. Interaction of S100A8/S100A9-arachidonic acid complexes with the scavenger receptor CD36 may facilitate fatty acid uptake by endothelial cells. Biochemistry 2001;40:241-8.

69 Chen X, Eksioglu EA, Zhou J, et al. Induction of myelodysplasia by myeloid-derived suppressor cells. J Clin Invest 2013;123:4595-611.

70 Tsai S-Y, Segovia JA, Chang T-H, et al. Regulation of TLR3 activation by S100A9. J Immunol 2015:195:4426-37.

71 Moles A, Murphy L, Wilson CL. A TLR2/S100A9/CXCL-2 signaling network is necessary for neutrophil recruitment in acute and chronic liver injury in the mouse. $J$ Hepatol 2014;60:782-91. 
72 Ryckman C, Vandal K, Rouleau P, et al. Proinflammatory activities of S100: proteins S100A8, S100A9, and S100A8/A9 induce neutrophil chemotaxis and adhesion. J Immunol 2003;170:3233-42.

73 Waldron KJ, Rutherford JC, Ford D, et al. Metalloproteins and metal sensing. Nature 2009;460:823-30.

74 Wang C, Zhang R, Wei X, et al. Metalloimmunology: the metal ion-controlled immunity. Adv Immunol 2020;145:187-241.

75 Kehl-Fie TE, Zhang Y, Moore JL, et al. MntABC and MntH contribute to systemic Staphylococcus aureus infection by competing with calprotectin for nutrient manganese. Infect Immun 2013;81:3395-405.

76 Diaz-Ochoa VE, Lam D, Lee CS, et al. Salmonella mitigates oxidative stress and Thrives in the inflamed gut by evading Calprotectin-Mediated manganese sequestration. Cell Host Microbe 2016;19:814-25.

77 Willers M, Ulas T, Völlger L, et al. S100A8 and S100A9 are important for postnatal development of gut microbiota and immune system in mice and infants. Gastroenterology 2020;159:2130-45.

78 De Filippo K, Neill DR, Mathies M, et al. A new protective role for S100A9 in regulation of neutrophil recruitment during invasive pneumococcal pneumonia. Faseb J 2014:28:3600-8.

79 Cesaro A, Anceriz N, Plante A, et al. An inflammation loop orchestrated by S100A9 and calprotectin is critical for development of arthritis. PLoS One 2012;7:e45478.

80 Simard J-C, Cesaro A, Chapeton-Montes J, et al. S100A8 and S100A9 induce cytokine expression and regulate the NLRP3 inflammasome via ROS-dependent activation of NF- $\kappa B(1$.$) . PLoS One 2013:8:e72138.$

$81 \mathrm{Gao} \mathrm{H}, \mathrm{Hou}$ J, Meng H, et al. Proinflammatory effects and mechanisms of calprotectin on human gingival fibroblasts. J Periodontal Res 2017;52:975-83.

82 Simard J-C, Noël C, Tessier PA, et al. Human S100A9 potentiates IL-8 production in response to GM-CSF or fMLP via activation of a different set of transcription factors in neutrophils. FEBS Lett 2014;588:2141-6.

83 Marinković G, Grauen Larsen H, Yndigegn T, et al. Inhibition of pro-inflammatory myeloid cell responses by short-term S100A9 blockade improves cardiac function after myocardial infarction. Eur Heart J 2019;40:2713-23.

84 Wu D-M, Wang S, Shen M, et al. S100A9 gene silencing inhibits the release of proinflammatory cytokines by blocking the IL-17 signalling pathway in mice with acute pancreatitis. J Cell Mol Med 2018;22:2378-89.

85 Holzinger D, Nippe N, Vogl T, et al. Myeloid-Related proteins 8 and 14 contribute to monosodium urate monohydrate crystal-induced inflammation in gout. Arthritis Rheumatol 2014;66:1327-39.

86 Yang J, Anholts J, Kolbe U, et al. Calcium-Binding proteins S100A8 and S100A9: investigation of their immune regulatory effect in myeloid cells. Int J Mo/ Sci 2018; 19:1833.

87 Zha H, Li X, Sun H, et al. S100A9 promotes the proliferation and migration of cervical cancer cells by inducing epithelial-mesenchymal transition and activating the Wnt/ß-catenin pathway. Int J Oncol 2019;55:35-44.

88 Qin F, Song Y, Li Z, et al. S100A8/A9 induces apoptosis and inhibits metastasis of CaSKi human cervical cancer cells. Pathol Oncol Res 2010;16:353-60.

89 Laouedj M, Tardif MR, Gil L, et al. S100A9 induces differentiation of acute myeloid leukemia cells through TLR4. Blood 2017;129:1980-90.

90 Yin L-M, Han X-J, Duan T-T, et al. Decreased S100A9 expression promoted rat airway smooth muscle cell proliferation by stimulating ROS generation and inhibiting p38 MAPK. Can Respir J 2016;2016:1-7.

91 Ghavami S, Rashedi I, Dattilo BM, et al. S100A8/A9 at low concentration promotes tumor cell growth via RAGE ligation and MAP kinase-dependent pathway. J Leukoc Biol 2008;83:1484-92.

92 Low D, Subramaniam R, Lin L, et al. Chitinase 3-like 1 induces survival and proliferation of intestinal epithelial cells during chronic inflammation and colitisassociated cancer by regulating S100A9. Oncotarget 2015:6:36535-50.

93 Wu P, Quan H, Kang J, et al. Downregulation of calcium-binding protein S100A9 inhibits hypopharyngeal cancer cell proliferation and invasion ability through inactivation of NF- $\kappa B$ signaling. Oncol Res 2017;25:1479-88.

94 Lin C-R, Wei T-YW, Tsai H-Y, et al. Glycosylation-Dependent interaction between CD69 and S100A8/S100A9 complex is required for regulatory T-cell differentiation. Faseb J 2015;29:5006-17.

95 Sakaguchi S, Sakaguchi N, Asano M. Immunologic self-tolerance maintained by activated T cells expressing IL-2 receptor alpha-chains (CD25). breakdown of a single mechanism of self-tolerance causes various autoimmune diseases. J Immunol 1995; 155:1151-64

96 Narumi K, Miyakawa R, Ueda R, et al. Proinflammatory proteins S100A8/S100A9 activate NK cells via interaction with RAGE. J Immunol 2015;194:5539-48.

97 Yui S, Mikami M, Tsurumaki K, et al. Growth-Inhibitory and apoptosis-inducing activities of calprotectin derived from inflammatory exudate cells on normal fibroblasts: regulation by metal ions. J Leukoc Biol 1997;61:50-7.

98 Sakaguchi M, Murata H, Aoyama Y, et al. Dnax-Activating protein 10 (DAP10) membrane adaptor associates with receptor for advanced glycation end products (RAGE) and modulates the RAGE-triggered signaling pathway in human keratinocytes. J Biol Chem 2014;289:23389-402.

99 McNeill E, Hogg N. S100A9 has a protective role in inflammation-induced skin carcinogenesis. Int J Cancer 2014;135:798-808.
100 Gebhardt C, Riehl A, Durchdewald M, et al. Rage signaling sustains inflammation and promotes tumor development. J Exp Med 2008:205:275-85.

101 Goyette J, Geczy CL. Inflammation-Associated S100 proteins: new mechanisms that regulate function. Amino Acids 2011:41:821-42.

102 Gopal R, Monin L, Torres D, et al. S100A8/A9 proteins mediate neutrophilic inflammation and lung pathology during tuberculosis. Am J Respir Crit Care Med 2013;188:1137-46

103 Tsai S-Y, Segovia JA, Chang T-H, et al. Damp molecule S100A9 acts as a molecular pattern to enhance inflammation during influenza A virus infection: role of DDX21 TRIF-TLR4-MyD88 pathway. PLoS Pathog 2014;10:e1003848.

104 Chimenti MS, Triggianese P, Botti E, et al. S100A8/A9 in psoriatic plaques from patients with psoriatic arthritis. J Int Med Res 2016:44:33-7.

105 Zhang X, Wei L, Wang J, et al. Suppression colitis and colitis-associated colon cancer by Anti-S100a9 antibody in mice. Front Immunol 2017;8:8

106 Lee $Y$, Jang S, Min J-K, et al. S100A8 and S100A9 are messengers in the crosstalk between epidermis and dermis modulating a psoriatic milieu in human skin. Biochem Biophys Res Commun 2012:423:647-53.

107 Martel BC, Litman T, Hald A, et al. Distinct molecular signatures of mild extrinsic and intrinsic atopic dermatitis. Exp Dermato/ 2016;25:453-9.

108 Raquil M-A, Anceriz N, Rouleau P, et al. Blockade of antimicrobial proteins S100A8 and S100A9 inhibits phagocyte migration to the alveoli in streptococcal pneumonia. J Immunol 2008:180:3366-74.

109 Ryckman C, McColl SR, Vandal K, et al. Role of S100A8 and S100A9 in neutrophil recruitment in response to monosodium urate monohydrate crystals in the air-pouch model of acute gouty arthritis. Arthritis Rheum 2003;48:2310-20.

110 Aranda CJ, Ocón B, Arredondo-Amador M, et al. Calprotectin protects against experimental colonic inflammation in mice. Br J Pharmacol 2018;175:3797-812.

111 Giudice V, Wu Z, Kajigaya S, et al. Circulating S100A8 and S100A9 protein levels in plasma of patients with acquired aplastic anemia and myelodysplastic syndromes. Cytokine 2019;113:462-5.

112 Yasar 0, Akcay T, Obek C, et al. Significance of S100A8, S100A9 and calprotectin levels in bladder cancer. Scand J Clin Lab Invest 2017;77:437-41.

113 Huang $H$, Huang Q, Tang T, et al. Clinical significance of calcium-binding protein S100A8 and S100A9 expression in non-small cell lung cancer. Thorac Cancer 2018;9:800-4.

114 Bao YI, Wang A, Mo J. S100A8/A9 is associated with estrogen receptor loss in breast cancer. Oncol Lett 2016;11:1936-42.

115 Nedjadi T, Evans A, Sheikh A, et al. S100A8 and S100A9 proteins form part of a paracrine feedback loop between pancreatic cancer cells and monocytes. BMC Cancer 2018;18:1255.

116 Grebhardt S, Müller-Decker K, Bestvater F, et al. Impact of S100A8/A9 expression on prostate cancer progression in vitro and in vivo. J Cell Physiol 2014;229:661-71.

117 De Ponti A, Wiechert L, Schneller D, et al. A pro-tumorigenic function of S100A8/A9 in carcinogen-induced hepatocellular carcinoma. Cancer Lett 2015:369:396-404.

118 Ichikawa M, Williams R, Wang L, et al. S100A8/A9 activate key genes and pathways in colon tumor progression. Mol Cancer Res 2011;9:133-48.

119 Hobbs JAR, May R, Tanousis K, et al. Myeloid cell function in MRP-14 (S100A9) null mice. Mol Cell Biol 2003:23:2564-76.

120 Vogl T, Stratis A, Wixler V, et al. Autoinhibitory regulation of S100A8/S100A9 alarmin activity locally restricts sterile inflammation. J Clin Invest 2018;128:1852-66.

121 Manitz M-P, Horst B, Seeliger S, et al. Loss of S100A9 (MRP14) results in reduced interleukin-8-induced CD11b surface expression, a polarized microfilament system, and diminished responsiveness to chemoattractants in vitro. Mol Cell Biol 2003;23:1034-43.

122 Passey RJ, Williams E, Lichanska AM. A null mutation in the inflammation-associated S100 protein S100A8 causes early resorption of the mouse embryo. J Immunol 1999:163:2209-16.

123 Baker JR, Jeffery R, May RD, et al. Distinct roles for S100A8 in early embryo development and in the maternal deciduum. Dev Dyn 2011:240:2194-203.

124 Cesaro A, Defrêne J, Lachhab A, et al. Enhanced myelopoiesis and aggravated arthritis in S100a8-deficient mice. PLoS One 2019:14:e0221528.

125 Defrêne J, Berrazouane S, Esparza N, et al. Deletion of S100a8 and S100aS Enhances Skin Hyperplasia and Promotes the Th17 Response in Imiquimod-Induced Psoriasis. J Immunol 2021;206:505-14.

126 Zhao J, Endoh I, Hsu K, et al. S100A8 modulates mast cell function and suppresses eosinophil migration in acute asthma. Antioxid Redox Signal 2011;14:1589-600.

127 Källberg E, Tahvili S, Ivars F, et al. Induction of S100A9 homodimer formation in vivo. Biochem Biophys Res Commun 2018;500:564-8.

128 Riva M, He Z, Källberg E, et al. Human S100A9 protein is stabilized by inflammatory stimuli via the formation of proteolytically-resistant homodimers. PLOS One 2013:8:e61832

129 Suchismita A, Jha A. IDDF2019-ABS-0129 Optimal cut-off value of fecal calprotectin for the evaluation of inflammatory bowel disease: an unsolved issue? Gut 2019;68:A85-6.

130 Tomkins C, Zeino Z, Nwokolo C, et al. PMO-243 Faecal calprotectin analysis: does the method matter? Gut 2012;61:A173.2-4.

131 Srinivas M, Eyre R, Ellis R, et al. PTU-243 Faecal calprotectin (FC) assays: comparison of four assays with clinical correlation. Gut 2012;61:A284.3-5. 
132 Henderson P, Anderson NH, Wilson DC. The diagnostic accuracy of fecal calprotectin during the investigation of suspected pediatric inflammatory bowel disease: a systematic review and meta-analysis. Am J Gastroenterol 2014;109:637-45.

133 Pirr S, Richter M, Fehlhaber B, et al. High amounts of S100-Alarmins confer antimicrobial activity on human breast milk targeting pathogens relevant in neonatal sepsis. Front Immunol 2017;8:8.

134 Soubieres A, Shandro B, Mathur J. PTH-125 The clinical utility and diagnostic accuracy of faecal calprotectin for IBD in paediatric patients. Gut 2019;68:A97.

135 Røseth AG, Fagerhol MK, Aadland E, et al. Assessment of the neutrophil dominating protein calprotectin in feces. A methodologic study. Scand J Gastroenterol 1992:27:793-8.

136 Desai D, Faubion WA, Sandborn WJ. Review article: biological activity markers in inflammatory bowel disease. Aliment Pharmacol Ther 2007:25:247-55.

137 Lasson A, Stotzer P-O, Öhman L, et al. The intra-individual variability of faecal calprotectin: a prospective study in patients with active ulcerative colitis. J Crohns Colitis 2015;9:26-32

138 Mosli MH, Zou G, Garg SK, et al. C-Reactive protein, fecal calprotectin, and stool lactoferrin for detection of endoscopic activity in symptomatic inflammatory bowe disease patients: a systematic review and meta-analysis. Am J Gastroenterol 2015;110:802-19.

139 Kyle BD, Agbor TA, Sharif S, et al. Fecal calprotectin, CRP and leucocytes in IBD patients: comparison of biomarkers with biopsy results. J Can Assoc Gastroenterol 2021:4:84-90.

140 Chin AC, Parkos CA. Neutrophil transepithelial migration and epithelial barrier function in IBD: potential targets for inhibiting neutrophil trafficking. Ann N Y Acad Sci 2006;1072:276-87.

141 Zhou GX, Liu ZJ. Potential roles of neutrophils in regulating intestinal mucosal inflammation of inflammatory bowel disease. J Dig Dis 2017:18:495-503.

142 Chen C-C, Huang J-L, Chang C-J, et al. Fecal calprotectin as a correlative marker in clinical severity of infectious diarrhea and usefulness in evaluating bacterial or viral pathogens in children. J Pediatr Gastroenterol Nutr 2012;55:541-7.

143 Nielsen HL, Engberg J, Ejlertsen T, et al. Evaluation of fecal calprotectin in Campylobacter concisus and Campylobacter jejuni/coli gastroenteritis. Scand J Gastroenterol 2013;48:633-5

144 Dróżdż M, Biesiada G, Pituch H, et al. The level of fecal calprotectin significantly correlates with Clostridium difficile infection severity. Folia Med Cracov 2019;59:53-65.

145 Eckard AR, Hughes HY, Hagood NL, et al. Fecal calprotectin is elevated in HIV and related to systemic inflammation. J Acquir Immune Defic Syndr 2021;86:231-9.

146 Effenberger M, Grabherr F, Mayr L, et al. Faecal calprotectin indicates intestinal inflammation in COVID-19. Gut 2020:69:1543-4.

147 Lehmann FS, Trapani F, Fueglistaler I, et al. Clinical and histopathological correlations of fecal calprotectin release in colorectal carcinoma. World J Gastroenterol 2014;20:4994-9

148 Zollner A, Schmiderer A, Reider SJ, et al. Faecal biomarkers in inflammatory bowel diseases: calprotectin versus Lipocalin-2-a comparative study. J Crohns Colitis 2021:15:43-54.

149 von Roon AC, Karamountzos L, Purkayastha S, et al. Diagnostic precision of fecal calprotectin for inflammatory bowel disease and colorectal malignancy. Am J Gastroenterol 2007;102:803-13.

150 Lin J-F, Chen J-M, Zuo J-H, et al. Meta-Analysis: fecal calprotectin for assessment of inflammatory bowel disease activity. Inflamm Bowel Dis 2014;20:1407-15.

151 D'Haens G, Ferrante M, Vermeire S, et al. Fecal calprotectin is a surrogate marker for endoscopic lesions in inflammatory bowel disease. Inflamm Bowel Dis 2012;18:2218-24.

152 Boon GJAM, Day AS, Mulder CJ, et al. Are faecal markers good indicators of mucosa healing in inflammatory bowel disease? World J Gastroentero/ 2015;21:11469-80.

153 Xiang J-Y, Ouyang Q, Li G-D, et al. Clinical value of fecal calprotectin in determining disease activity of ulcerative colitis. World J Gastroenterol 2008;14:53-7

154 Pergialiotis V, Konstantopoulos P, Karampetsou N, et al. Calprotectin levels in necrotizing enterocolitis: a systematic review of the literature. Inflamm Res 2016;65:847-52.

155 Malik MN, Rafae A, Durer C, et al. Fecal calprotectin as a diagnostic and prognostic biomarker for gastrointestinal graft versus host disease: a systematic review of literature. Cureus 2019;11:e4143.

156 Tibble JA, Sigthorsson G, Foster R, et al. High prevalence of NSAID enteropathy as shown by a simple faecal test. Gut 1999;45:362-6

157 Manz M, Burri E, Rothen C, et al. Value of fecal calprotectin in the evaluation of patients with abdominal discomfort: an observational study. BMC Gastroenterol 2012:12:5.

158 Summerton CB, Longlands MG, Wiener K, et al. Faecal calprotectin: a marker of inflammation throughout the intestinal tract. Eur J Gastroenterol Hepatol 2002;14:841-5.

159 Lundgren D, Eklöf V, Palmqvist R, et al. Proton pump inhibitor use is associated with elevated faecal calprotectin levels. A cross-sectional study on subjects referred for colonoscopy. Scand J Gastroenterol 2019;54:152-7.
160 Weis S, Schwiertz A, Unger MM, et al. Effect of Parkinson's disease and related medications on the composition of the fecal bacterial microbiota. NPJ Parkinsons Dis 2019;5:28

161 Vavricka SR, Heinrich H, Buetikofer S, et al. The Vampire Study: Significant elevation of faecal calprotectin in healthy volunteers after $300 \mathrm{ml}$ blood ingestion mimicking upper gastrointestinal bleeding. United European Gastroenterol J 2018;6:1007-14.

162 Lee SH, Mainman H, Borthwick H, et al. PTH-094 Faecal Calprotectin Testing in Primary and Secondary Care - are the Current Manufacturer'S Cut-Off Levels Clinically Useful? Gut 2013;62:A249.2-A249.

163 Lozoya Angulo ME, de Las Heras Gómez I, Martinez Villanueva M, et al. Faeca calprotectin, an useful marker in discriminating between inflammatory bowel disease and functional gastrointestinal disorders. Gastroenterol Hepatol 2017:40:125-31.

164 Wright K, Kennedy J, Materacki L, et al. PTU-131 Intermediate Faecal Calprotectin: A Positive Or'negative Result? Observations of A Retrospective Study. Gut 2016:65:A121.2-2

165 Zittan E, Kelly OB, Kirsch R, et al. Low fecal calprotectin correlates with histologica remission and mucosal healing in ulcerative colitis and colonic Crohn's disease. Inflamm Bowel Dis 2016;22:623-30.

166 Pavlidis P, Cockroft A, Choong L. PTH-095 Persistently elevated faecal calprotectin in the first 12 months of crohn's diagnosis predicts the need for surgery: a nested case-control study. Gut 2017;66:A253-A53.

167 Schoepfer AM, Beglinger C, Straumann A, et al. Fecal calprotectin more accurately reflects endoscopic activity of ulcerative colitis than the Lichtiger index, $\mathrm{C}$ reactive protein, platelets, hemoglobin, and blood leukocytes. Inflamm Bowel Dis 2013;19:332-41.

168 Gisbert JP, Bermejo F, Pérez-Calle J-L, et al. Fecal calprotectin and lactoferrin for the prediction of inflammatory bowel disease relapse. Inflamm Bowel Dis 2009;15:1190-8.

169 Mao R, Xiao Y-lian, Gao X, et al. Fecal calprotectin in predicting relapse of inflammatory bowel diseases: a meta-analysis of prospective studies. Inflamm Bowel Dis 2012;18:1894-9.

170 Costa F, Mumolo MG, Ceccarelli L, et al. Calprotectin is a stronger predictive marker of relapse in ulcerative colitis than in Crohn's disease. Gut 2005:54:364-8.

171 Toke N, Ramaswamy P, Panackel C. IDDF2019-ABS-0346 Utility of inflammatory markers in the management of inflammatory bowel disease and their correlation with disease activity indices. Gut 2019:68:A122-A22.

172 De Vos M, Louis EJ, Jahnsen J, et al. Consecutive fecal calprotectin measurements to predict relapse in patients with ulcerative colitis receiving infliximab maintenance therapy. Inflamm Bowel Dis 2013;19:2111-7.

173 Lobatón T, Rodríguez-Moranta F, Lopez A, et al. A new rapid quantitative test for fecal calprotectin predicts endoscopic activity in ulcerative colitis. Inflamm Bowel Dis 2013;19:1034-42.

174 Turner D, Ricciuto A, Lewis A, et al. STRIDE-II: an update on the selecting therapeutic targets in inflammatory bowel disease (STRIDE) initiative of the International organization for the study of IBD (IOIBD): determining therapeutic goals for Treat-toTarget strategies in IBD. Gastroenterology 2021;160:1570-83.

175 Yamamoto T, Shimoyama T, Matsumoto K. Consecutive monitoring of faecal calprotectin during mesalazine suppository therapy for active rectal inflammation in ulcerative colitis. Aliment Pharmacol Ther 2015;42:549-58.

176 Patel A, Panchal H, Dubinsky MC. Fecal calprotectin levels predict histological healing in ulcerative colitis. Inflamm Bowel Dis 2017;23:1600-4.

177 Theede K, Holck S, Ibsen P, et al. Fecal calprotectin predicts relapse and histological mucosal healing in ulcerative colitis. Inflamm Bowel Dis 2016;22:1042-8

178 Perowne R, Lamb C, Speight RA, et al. PWE-095 Faecal Calprotectin Is Useful In Predicting Long Term Disease Recurrence In Post-operative Crohn's. Gut2014;6 3:A165.2-6.

179 Hukkinen M, Pakarinen MP, Merras-Salmio L, et al. Fecal calprotectin in the prediction of postoperative recurrence of Crohn's disease in children and adolescents. J Pediatr Surg 2016;51:1467-72.

180 Tham YS, Yung DE, Fay $S$, et al. Fecal calprotectin for detection of postoperative endoscopic recurrence in Crohn's disease: systematic review and meta-analysis. Therap Adv Gastroenterol 2018;11:1756284818785571.

181 Torres J, Bonovas S, Doherty G, et al. ECCO Guidelines on Therapeutics in Crohn's Disease: Medical Treatment. Journal of Crohn's colitis 2020:14:4-22.

182 Adamina M, Bonovas S, Raine T, et al. ECCO Guidelines on Therapeutics in Crohn's Disease: Surgical Treatment. Journal of Crohn's colitis 2020;14:155-68.

183 Kalla R, Kennedy NA, Ventham NT, et al. PWE-025 Serum Calprotectin - A Novel Diagnostic and Prognostic Marker in Inflammatory Bowel Diseases. Gut 2016;65:A1 50.1-A150

184 Meuwis M-A, Vernier-Massouille G, Grimaud JC, et al. Serum calprotectin as a biomarker for Crohn's disease. J Crohns Colitis 2013:7:e678-83.

185 Leach ST, Yang Z, Messina I, et al. Serum and mucosal S100 proteins, calprotectin (S100A8/S100A9) and S100A12, are elevated at diagnosis in children with inflammatory bowel disease. Scand J Gastroenterol 2007;42:1321-31. 
186 Qian M, Song N-J. Serum calprotectin correlates with risk and disease severity in psoriasis patients and the decrease of calprotectin predicts better response to tumor necrosis factor inhibitors. Eur Rev Med Pharmacol Sci 2018;22:4299-309.

187 Jarlborg M, Courvoisier DS, Lamacchia C, et al. Serum calprotectin: a promising biomarker in rheumatoid arthritis and axial spondyloarthritis. Arthritis Res Ther 2020;22:105.

188 Wakiya R, Kameda T, Ueeda K, et al. Hydroxychloroquine modulates elevated expression of $\mathrm{S} 100$ proteins in systemic lupus erythematosus. Lupus 2019;28:826-33

189 Oktayoglu P, Bozkurt M, Mete N, et al. Elevated serum levels of calprotectin (myeloid-related protein 8/14) in patients with ankylosing spondylitis and its association with disease activity and quality of life. J Investig Med 2014;62:880-4.

190 Lira-Junior R, Öztürk Veli Özgen, Emingil G, et al. Salivary and serum markers related to innate immunity in generalized aggressive periodontitis. J Periodontol 2017:88:1339-47.

191 Argyris PP, Slama Z, Malz C, et al. Intracellular calprotectin (S100A8/A9) controls epithelial differentiation and caspase-mediated cleavage of EGFR in head and neck squamous cell carcinoma. Oral Oncol 2019;95:1-10.
192 Sokolova MV, Simon D, Nas K, et al. A set of serum markers detecting systemic inflammation in psoriatic skin, entheseal, and joint disease in the absence of C-reactive protein and its link to clinical disease manifestations. Arthritis Res Ther 2020;22:26.

193 Pedersen L, Nybo M, Poulsen MK, et al. Plasma calprotectin and its association with cardiovascular disease manifestations, obesity and the metabolic syndrome in type 2 diabetes mellitus patients. BMC Cardiovasc Disord 2014;14:196.

194 Calcaterra V, De Amici M, Leonard MM, et al. Serum calprotectin level in children: marker of obesity and its metabolic complications. Ann Nutr Metab 2018;73:177-83.

195 Grand A, Rochette E, Dutheil F, et al. Body mass index and calprotectin blood level correlation in healthy children: an individual patient data meta-analysis. J Clin Med 2020;9:857.

196 Silvin A, Chapuis N, Dunsmore G, et al. Elevated calprotectin and abnormal myeloid cell subsets discriminate severe from mild COVID-19. Cell 2020;182:1401-18.

197 Gao S, Yang Y, Fu Y, et al. Diagnostic and prognostic value of myeloid-related protein complex 8/14 for sepsis. Am J Emerg Med 2015;33:1278-82. 